\title{
Effect of Yb Concentration on the Structural, Magnetic and Optoelectronic Properties of Yb Doped ZnO: First Principles Calculation
}

\section{Mohamed Achehboune ( $\nabla$ achehboune.mohamed01@gmail.com )}

Universite Sidi Mohamed Ben Abdellah Faculte des Sciences Dhar El Mahraz-Fes https://orcid.org/00000002-7716-8085

\section{Mohammed Khenfouch}

Ibn Zohr University: Universite Ibn Zohr

\section{Issam Boukhoubza}

Universite Sidi Mohamed Ben Abdellah Faculte des Sciences Dhar El Mahraz-Fes

\section{Issam Derkaoui}

Universite Sidi Mohamed Ben Abdellah Faculte des Sciences Dhar El Mahraz-Fes

\section{Bakang Moses Mothudi}

University of South Africa - Florida Campus: University of South Africa - Science Campus

\section{Izeddine Zorkani}

Universite Sidi Mohamed Ben Abdellah Faculte des Sciences Dhar El Mahraz-Fes

\section{Anouar Jorio}

Universite Sidi Mohamed Ben Abdellah Faculte des Sciences Dhar El Mahraz-Fes

\section{Research Article}

Keywords: First principles, DFT+U, doped ZnO, electronic structure, magnetic properties, optical properties.

Posted Date: September 16th, 2021

DOI: https://doi.org/10.21203/rs.3.rs-877060/v1

License: (a) (i) This work is licensed under a Creative Commons Attribution 4.0 International License. Read Full License

Version of Record: A version of this preprint was published at Optical and Quantum Electronics on November 13th, 2021. See the published version at https://doi.org/10.1007/s11082-021-03369-x. 


\section{Abstract}

Density functional theory-based investigation of the electronic, magnetic, and optical characteristics in pure and ytterbium $(\mathrm{Yb})$ doped $\mathrm{ZnO}$ has been carried out by the plane-wave pseudopotential technique with generalized gradient approximation. The calculated lattice parameters and band gap of pure $\mathrm{ZnO}$ are in good agreement with the experimental results. The energy band-gap increases with the increase of $\mathrm{Yb}$ concentration. The Fermi level moves upward into the conduction band after doping with $\mathrm{Yb}$, which shows the properties of an n-type se miconductor. New defects were created in the band-gap near the conduction band attributed to the $\mathrm{Yb}-4 \mathrm{f}$ states. The magnetic properties of $\mathrm{ZnO}$ were found to be affected by $\mathrm{Yb}$ doping; ferromagnetic property was observed for $4.17 \% \mathrm{Yb}$ due to spin polarization of $\mathrm{Yb}-4 \mathrm{f}$ electrons. The calculated optical properties imply that $\mathrm{Yb}$ doped causes a blue shift of the absorption peaks, significantly enhances the absorption of the visible light, and the blue shift of the reflectivity spectrum was observed. Besides, a better transmittance of approximately $88 \%$ was observed for $4.17 \% \mathrm{Yb}$ doped $\mathrm{ZnO}$ system. The refractive index and the extinction coefficient were observed to decrease as the $\mathrm{Yb}$ dopant concentration increased. As a result, we believe that our findings will be useful in understanding the doping impact in $\mathrm{ZnO}$ and will motivate further theoretical research.

\section{Introduction}

Recently, studies are increasingly focusing on developing the $\mathrm{ZnO}$ semiconductor as a functional material for optoelectronic and electronic devices. As a wide band gap semiconductor about $3.37 \mathrm{eV}$ and a large exciton binding energy ( $\sim 60 \mathrm{meV}$ ) at room temperature, $\mathrm{ZnO}$ can be used in many potential applications such as blue and ultraviolet (UV) lasers, light-emitting diodes, Spintronics and transparent electrodes in solar cells (Look et al. 1998; Look 2006; Namgung et al. 2019). Because doping ZnO is one of the most significant issues in order to design $\mathrm{ZnO}$ based devices, rare-earth (RE) doped $\mathrm{ZnO}$ has become recently the focus of numerous studies owing to their unique optical properties and promising applications in optoelectronic devices (Röder et al. 2019; Chen et al. 2019; López-Mena et al. 2021). Rare earth generates great interest due to the $4 \mathrm{f}-4 \mathrm{f}$ intrashell transitions which provide intense emission lines in the UV, visible, and infrared (IR) regions and improve the luminescence efficiency through energy transfer processes (Daksh and Agrawal 2016). Because it is one of the rare earth elements, $\mathrm{Yb}$ can improve the optical and electrical properties of $\mathrm{ZnO}$. Many experimental studies regarding the influence of $\mathrm{Yb}$ doping content on the structural, optical and electrical properties of $\mathrm{ZnO}$ have been reported. Cerrato et al. (Cerrato et al. 2020) investigated the role of the $\mathrm{Yb}$ dopant in the photoactivity of $\mathrm{ZnO}$, finding that with a small amount of $\mathrm{Yb}$, the photoactivity of $\mathrm{ZnO}$ was enhanced. Heng et al. (Heng et al. 2020) found that for concentrations down to 0.1 at\%. of Yb, the near bandedge emission PL of pure ZnO was increased. In another study (Heng et al. 2017), he found that the ultra violet emission of the sputtered $\mathrm{ZnO}$ was increased 100 times after introducing 5 . at\% of $\mathrm{Yb}$. A recent systematic study conducted by López-Mena et al. (López-Mena et al. 2020) investigated the effect of ytterbium doping on the structural, morphological and optical properties of $\mathrm{ZnO}$ thin films, their findings suggest that $\mathrm{Yb}$-doped $\mathrm{ZnO}$ thin films are suitable for optoelectronic devices, solar cells. Given the large number of experimental studies on $\mathrm{Yb}$-doped $\mathrm{ZnO}$, there is still very limited theoretical research on the structural and optical properties of Yb-doped ZnO. For example, Khuili et al. (Khuili et al. 2020) reported a comparative study on of structural, optical and electrical properties of rare earth (Yb, Tm, Ce) doped ZnO 
finding that the band gap increased after doping and the Fermi level has been shifted to the conduction band, revealing n-type characters. In this regard, this study aims to develop a theoretical framework for understanding the effect of $\mathrm{Yb}$ concentration on the electronic structure, magnetic and optical properties of $\mathrm{ZnO}$ using the first-principles density functional theory. We believe that this work could support the future design of $\mathrm{ZnO}$ materials by providing significant insight into the microscopic characteristics of the materials, and will also encourage further theoretical investigations.

\section{Models And Calculation Method}

Pure $\mathrm{ZnO}$ exhibits a hexagonal wurtzite structure which belong to the P63mc space group and has a symmetry of C6v-4. Analysis was performed using Yb concentrations of 4.17, 6.25, and $12.5 \mathrm{at}$. \% and the structure of the doped $\mathrm{ZnO}$ systems was hexagonal wurtzite. Based on the primitive cell, a $(3 \times 2 \times 2),(2 \times 2 \times$ $2)$ and $(2 \times 2 \times 1) Z n O$ supercells were constructed as the models of the $\mathrm{ZnO}$. Figure 1 a shows a pure $\mathrm{ZnO}$, Fig. $1 \mathrm{~b}$ shows $\mathrm{Yb}$-doped $\mathrm{ZnO}$, which corresponds to $\mathrm{Zn}_{0.958} \mathrm{Yb}_{0.0417} \mathrm{O}$. Figure $1 \mathrm{c}$, on the other hand, shows $\mathrm{Yb}$ doped $\mathrm{ZnO}$ which corresponds to $\mathrm{Zn}_{0.9375} \mathrm{Yb}_{0.0625} \mathrm{O}$. Figure $1 \mathrm{~d}$, on the other hand shows a $\mathrm{Yb}$ doped $\mathrm{ZnO}$ which corresponds to $\mathrm{Zn}_{0.875} \mathrm{Yb}_{0 \cdot 125} \mathrm{O}$ where one $\mathrm{Yb}$ atom substituting one of the $\mathrm{Zn}$ atoms. These models correspond to 4.17 at\% 6.25 at\% and $12.5 \mathrm{at} \%$ of $\mathrm{Yb}$ in $\mathrm{ZnO}$.

The Cambridge Serial Total Energy Package (CASTEP) module, which is based on density functional theory (DFT), was used to do all computations in this work (Clark et al. 2005). The generalized gradient approximation with the generalized gradient approximation of Perdew-Burke-Ernzerhof (Perdew et al. 1996) (GGA-PBE) and the GGA + U approximation were used to perform geometry optimization and energy calculations for all systems. Structural optimization was performed on each model prior to calculating their electronic and optical properties. Moreover, the plane-wave ultrasoft pseudopotential method (Vanderbilt 1990) with valence electron configurations of $4 s^{2} 3 d^{10}$ for $Z n, 2 s^{2} 2 p^{4}$ for 0 , and $4 f^{12} 5 s^{2} 5 p^{6} 6 s^{2}$ for Er was used to describe the interactions between the ionic core and valence electrons and allow the present calculation to be performed with a cut-off energy of $500 \mathrm{eV}$ (Ma et al. 2013). The Brillouin zone integrations generated, automatically by the Monkhorst-Pack method were performed over a $5 \times 5 \times 4$ grid size for pure $\mathrm{ZnO}$ (Harun et al. 2017) and $4 \times 4 \times 2$ grid size for Yb-doped ZnO (Li et al. 2011). The DFT $+U$ method was adopted to describe the electronic structures accurately, by applying Hubbard $U$ correction to the $Z n-3 d$ states and 0-2pstates. According to Wu et al. (Wu et al. 2013), the Up, $\mathrm{O}$ value of $7 \mathrm{eV}$ for oxide materials is appropriate for first principles calculations. Zn-3d and 0-2p's U values were set to 10.00 and $7.00 \mathrm{eV}$, respectively, while $\mathrm{Yb}-4 \mathrm{f}$ 's $\mathrm{U}$ value was tuned to $6.00 \mathrm{eV}$. The self-consistent iteration convergence threshold was set at $10^{-5} \mathrm{eV} /$ atom, and all lattice constants and atomic locations for each supercell were totally relaxed until the maximal force on each atom was less than $0.03 \mathrm{eV} / \AA$, the internal stress was below 0.05 $\mathrm{GPa}$, and the displacement of each atom was below $0.01 \AA$.

The optical properties of the studied systems including absorption coefficient $a(\omega)$ and reflectivity $R(\omega)$ can be obtained on the basis of complex dielectric function $\varepsilon(\omega)=\varepsilon_{1}(\omega)+i \varepsilon_{2}(\omega)$ where $\varepsilon_{1}(\omega)$ and $\varepsilon_{2}(\omega)$ are the real and imaginary part which can be calculated from the Kramers-Kronig's equation (Li et al. 2009) as follows : 
Where $\omega$ is the incident photon frequency, $\rho_{o}$ is the polarization response, $u$ is the vector defining the polarization of incident electric filed, $\mathrm{e}$ is the electronic charge, and $\Omega$ is the unit cell volume. The subscripts $C$ and $\mathrm{V}$ refer to the conduction and valence bands, respectively.

The transmittance was calculated from the absorption coefficient and reflectivity and can be given by:

Where $\mathrm{T}$ represents transmittance, $\mathrm{a}$ and $\mathrm{R}$ represent respectively the absorption coefficient and reflectivity, and $d$ represents the film thickness which was set at $250 \mathrm{~nm}$ in this study.

\section{Results And Discussion}

\subsection{Structural Properties}

In order to evaluate the validity of the experimental data, we firstly performed an optimization of the optimum structures of pure $\mathrm{ZnO}, \mathrm{Yb}$ doped $\mathrm{ZnO}$ with various $\mathrm{Yb}$ concentrations. The calculated lattice parameters $\mathrm{a}, \mathrm{c}$ and $\mathrm{c} / \mathrm{a}$ for the optimized pure $\mathrm{ZnO}$ are respectively, $\mathrm{a}=3.249 \AA \mathrm{c}=5.216 \AA$, and $\mathrm{c} / \mathrm{a}=1.605$ which are in good agreement with the experimental values [(Farhat et al. 2018; Bouhouche et al. 2018; Naik et al. 2020; Achehboune et al. 2021), and in good agreement with other theoretical calculations (Khuili et al. 2020; Meng et al. 2017), indicating that our calculations are reliable and prove the validity of our model.

Table 1 shows a summary of the structural parameters of $\mathrm{ZnO}$ doped with different concentrations of $\mathrm{Yb}$. It was observed that the lattice parameters a and $\mathrm{c}$ increased with increasing $\mathrm{Yb}$ concentration, and consequently, the unit cell volume was increased. This result is consistent with another theoretical result (Khuili et al. 2020), as well as the successful preparation in experimental results (Senol 2016). This can be due to the difference in ionic radius between $\mathrm{Yb}\left(0.87 \mathrm{~A}^{\circ}\right)$ and $\mathrm{Zn}\left(0.74 \mathrm{~A}^{\circ}\right)$, contributing to crystal lattice expanding due to the distortion of the crystal lattice, the increase in volume cell is due to the repulsion between $\mathrm{Zn}$ and $\mathrm{Yb}$, which produces additional cell volume expansion. The total energy values showed that the geometric configuration of the pure $\mathrm{ZnO}$ is that of the most stable structure. The $\mathrm{Zn}-\mathrm{O}$ bond length decreased slightly with increasing $\mathrm{Yb}$ content, whereas the $\mathrm{Yb}-\mathrm{O}$ bond length decreased with increasing $\mathrm{Yb}$ 
concentration. Furthermore, the Mulliken charge determines the amount of electron density sheared within such a crystal lattice by an atom, in which more positive values mean that more electrons are contributed by the associated atom. This indicates that the $\mathrm{Yb}$ dopant contributes more electrons than $\mathrm{Zn}$ because of the Mulliken charge values for $\mathrm{Yb}$ that are more positive than those of $\mathrm{Zn}$, and the actual values of the charge interaction $\mathrm{Yb}-\mathrm{O}$ are higher than those of $\mathrm{Zn}-\mathrm{O}$.

Table 1

Calculated cell parameters, volume, total energy, bond length, and Mulliken charges of pure $\mathrm{ZnO}$, and ZnO doped with various $\mathrm{Yb}$ concentrations.

\begin{tabular}{|c|c|c|c|c|c|c|c|c|c|}
\hline & \multicolumn{4}{|c|}{$\begin{array}{l}\text { Cell } \\
\text { parameters }\end{array}$} & \multicolumn{2}{|c|}{ Bond length $\left(A^{\circ}\right)$} & \multicolumn{3}{|c|}{ Mulliken charges } \\
\hline & $a\left(A^{\circ}\right)$ & $c\left(A^{\circ}\right)$ & $\begin{array}{l}\text { Volume } \\
\left(A^{\circ 3}\right)\end{array}$ & $\begin{array}{l}\text { Total } \\
\text { energy } \\
\text { (eV) }\end{array}$ & Zn-O & $\mathrm{Yb}-\mathrm{O}$ & $\mathrm{Zn}$ & $\mathrm{Yb}$ & 0 \\
\hline Pure ZnO & 3.249 & 5.216 & 47.719 & -4292.7 & 2.00517 & - & 0.81 & - & -0.81 \\
\hline $\begin{array}{l}\mathrm{Zn}_{0.958} \mathrm{Yb}_{0.0417} \mathrm{O} \\
(4.17 \%)\end{array}$ & 3.287 & 5.262 & 49.235 & -4685.2 & 2.02700 & 2.19983 & 0.82 & 0.80 & -0.81 \\
\hline $\begin{array}{l}\mathrm{Zn}_{0.937} \mathrm{Yb}_{0.0625} \mathrm{O} \\
(6.25 \%)\end{array}$ & 3.309 & 5.351 & 50.761 & -4880.54 & 2.04431 & 2.19913 & 0.81 & 0.79 & -0.81 \\
\hline $\begin{array}{l}\mathrm{Zn}_{0.875} \mathrm{Yb}_{0.125} \mathrm{O} \\
(12.5 \%)\end{array}$ & 3.343 & 5.378 & 52.08 & -5466.38 & 2.03831 & 2.18398 & 0.82 & 0.78 & -0.80 \\
\hline
\end{tabular}

\subsection{Electronic Properties}

\section{Band structure}

To study the effect of $\mathrm{Yb}$ doping concentrations, we have firstly calculated the band structure of pure $\mathrm{ZnO}$. Figure $2 \mathrm{a}$ shows the calculated band energy structure of pure $\mathrm{ZnO}$. As observed, pure $\mathrm{ZnO}$ exhibits a direct band gap; the valence band maximum and the conduction band minimum are located at the $G$ point of the Brillouin zone. An estimated $0.74 \mathrm{eV}$ band gap of pure $\mathrm{ZnO}$ was achieved using only DFT calculations, which is far from the experimental value of 3.37eV (Özgür et al. 2005). In several studies (Yao et al. 2012; Xia et al. 2014; Farooq et al. 2016; Wen et al. 2018), the estimated energy band gap of ZnO using only GGA is between 0.74 and $0.81 \mathrm{eV}$. The underestimation of the band gap is provided by the strong $\mathrm{p}$ - $\mathrm{d}$ coupling. To correct this underestimation, we used $\mathrm{GGA}+\mathrm{U}$ to affect the inaccurate description of strongly localized electrons.

Therefore, the GGA + U method can help us to obtain more accurate optical properties. The calculated optical band gap for pure $\mathrm{ZnO}$ is $3.38 \mathrm{eV}$, which is in line with results reported in the experiment and other theoretical calculations [Ma et al. 2013; Obeid et al. 2019; Wang et al. 2020). The results of the band structures of pure and $\mathrm{Yb}$ doped $\mathrm{ZnO}$ with various concentrations are illustrated in Fig. 2. It can be observed from the Fig. 2b-d that the structures have a direct band gap whose value increases with increasing $\mathrm{Yb}$ concentration. It has been determined that $\mathrm{Zn}_{0.9583} \mathrm{Yb}_{0.0417} \mathrm{O}, \mathrm{Zn}_{0.9375} \mathrm{Yb}_{0.0625} \mathrm{O}$ and $\mathrm{Zn}_{0.875} \mathrm{Yb}_{0.125} \mathrm{O}$, band gaps are $3.40 \mathrm{eV}, 3.65$ $\mathrm{eV}$ and $3.84 \mathrm{eV}$, respectively, which are wider than pure $\mathrm{ZnO}$. This is consistent with the experimental findings of Ref. (López-Mena et al. 2020) which attributed the increase in the optical band to the lengths of the reduction in the $\mathrm{Zn}-\mathrm{O}$ bond lengths. Moreover, new occupied states appeared between the conduction band 
and the Fermi level attributed to the $4 \mathrm{f}$ orbitals of the $\mathrm{Yb}$ dopant, which are slightly shifted to lower energy as we increase the $\mathrm{Yb}$ concentration. It is also clear that the $\mathrm{Yb}$-doped $\mathrm{ZnO}$ system is an $\mathrm{n}$-type degenerate semiconductor because of the Fermi level that enters the conduction band to varying degrees and also due to the donor states created close to the conduction bands. A similar behavior was observed in (Daksh and Agrawal 2016; Wen et al. 2018; Wang et al. 2020). The introduction to Yb ions in ZnO system caused the band gap to increase due to the Burstein-Mott effect (Burstein 1954; Moss 1954).

\section{Density of states}

Further insight into the contributions of different states to the energy bands is given by the total state density (TDOS) and partial state density (PDOS). Figure 3 presents the total density of states (TDOS) and partial density of states (PDOS) of the pure $\mathrm{ZnO}$ and $\mathrm{Yb}$-doped $\mathrm{ZnO}$ system. It can be observed from Fig. 3a that the valence band of pure $\mathrm{ZnO}$ is mainly composed of the $3 \mathrm{~d}$ state of $\mathrm{Zn}$ and the $2 \mathrm{p}$ state of $\mathrm{O}$ and the conduction band is mainly composed of the $4 \mathrm{~s}$ state of $\mathrm{Zn}$ and the $2 \mathrm{~s}$ state of $\mathrm{O}$. The valence band located between 15.5 and $0 \mathrm{eV}$ is divided into three parts. Within the range of -5.4 to $0 \mathrm{eV}$, it is mainly composed of $02 p$ with a minor contribution from the $\mathrm{Zn} 3 \mathrm{~d}$ states, resulting in $\mathrm{d}-\mathrm{p}$ coupling. On the other hand, the valence bands within the range of 8.7 to $5.4 \mathrm{eV}$ are mainly composed of $\mathrm{Zn} 3 \mathrm{~d}$ and partial $\mathrm{O} 2 \mathrm{p}$ states. Lastly, an isolated band in the range of -15.5 to $-13.8 \mathrm{eV}$ at the valence band is formed with $02 \mathrm{~s}$ state. The composition of conduction bands, on the other hand, is consistent with the total density of $\mathrm{ZnO}$ in that they are mainly formed by the $\mathrm{Zn} 4 \mathrm{~s}$ and $\mathrm{O} 2 \mathrm{p}$ states. For the $\mathrm{ZnO}$ doped with $\mathrm{Yb}$ shown in Fig. 3b-d, we observe that the valence band shifted towards low energies compared to pure $\mathrm{ZnO}$ and continues to shift with increasing amount of $\mathrm{Yb}$. It was also observed that the PDOS of $\mathrm{Yb}$-doped $\mathrm{ZnO}$ systems present occupied states at near Fermi level, which mainly come from the $\mathrm{Yb}-4 \mathrm{f}$ orbital. Moreover, the conduction band mainly results from $\mathrm{Yb}$ $5 \mathrm{~d}$ and 0-2p orbitals. Consequently, the band structure and DOS show that the increase of Yb doping concentration causes the Fermi level to shift to the conduction band and the DOS to move to lower energy, and the existence of occupied states around the Fermi level will basically determine the optoelectronic characteristics of these materials, indicating that doping with $\mathrm{Yb}$ can obtain a high-quality n-type $\mathrm{ZnO}$.

\subsection{Magnetic Properties}

The partial density of states (PDOS) with spin polarization was performed for all materials in order to illustrate the magnetic mechanism and the effect of $\mathrm{Yb}$ as dopant in $\mathrm{ZnO}$ with different $\mathrm{Yb}$ concentrations. As shown in Fig. 4, the spin-up and spin-down of the total density of states of undoped ZnO were symmetric, indicating that $\mathrm{ZnO}$ is a non-magnetic material; the calculated total magnetic moment of pure $\mathrm{ZnO}$ is 0.00018 $\mu \mathrm{B}$. However, for $4.17 \%$ of $\mathrm{Yb}$-doped $\mathrm{ZnO}$ it is noticed that the spin-up and spin-down channels were asymmetrical and show that $\mathrm{Yb}$-doped $\mathrm{ZnO}$ has a ferromagnetic property with an optimal concentration of $4.17 \%$, which exhibiting magnetism behavior in $\mathrm{ZnO}^{-\mathrm{Yb}_{\mathrm{Zn}}}$ system. It is clear from the figure that there is a clear spin polarization between the partial DOS of the two spin channels near the Fermi level due to spin polarization of $4 \mathrm{f}$ electrons of $\mathrm{Yb}$ atom (inset image); the total magnetic moment was found to be increased to $0.048 \mu \mathrm{B}$. However, as the concentration increased up to $6.25 \%$, the spin up and spin down became symmetrical, and the magnetic moment of the doped $\mathrm{ZnO}$ structure was increased; this behavior can be explained by the increase in the antiferromagnetic superexchange interaction along with $\mathrm{Yb}$ doping as a result of the decrease in the distance between the $\mathrm{Yb}$ ions. In addition, these two system show an n-type 
degenerate semiconductor as shown from Fig. 2. The calculated total magnetic moment became 0.0087, $0.0052 \mu \mathrm{B}$ for $6.25 \%$ and $12.5 \%$ respectively. These current findings show the characteristics of diluted magnetic semiconductors (DMSs) and can help with the design and preparation of new ZnO-based magnetooptoelectronic applications.

\subsection{Optical Properties}

\section{Dielectric Function}

The imaginary part of the dielectric function is a critical characteristic of the optical properties of any material, which can explain the energy required for the electrons to transit from the valence band to the conduction band. Figure 5 illustrates the imaginary parts of the dielectric functions of pure $\mathrm{ZnO}, \mathrm{Yb}$-doped $\mathrm{ZnO}$ with different concentrations of $\mathrm{Yb}$. As can be seen in Fig. 5, pure $\mathrm{ZnO}$ has three main peaks in $\varepsilon_{2}(\omega)$, which is in good agreement with the experimental results (Hengehold et al. 1970) and the theoretical calculations (Wang et al. 2020). The first peak around $5 \mathrm{eV}$ comes mainly from transition between the $\mathrm{Zn} 3 \mathrm{~d}$ and $02 p$ orbitals. The second peak energy around $10 \mathrm{eV}$ comes from transition between $\mathrm{Zn}-3 \mathrm{~d}$ and $0-2 \mathrm{~s}$ orbitals and the third one around $15 \mathrm{eV}$ correspond to the transitions of $\mathrm{Zn} 4 \mathrm{p}$ state to $\mathrm{O} 2 \mathrm{p}$ state.

For Yb-doped ZnO systems, we can find that the main dielectric peaks around $15 \mathrm{eV}$ are significantly weakened and shift to lower energies with increasing $\mathrm{Yb}$ concentration, indicating that the range of absorption frequency narrows and the average optical transmittance increases. However, the peak around 10 $\mathrm{eV}$ increases with increasing $\mathrm{Yb}$ concentration due to the strong hybridization between the $\mathrm{Zn}-3 \mathrm{~d}$ and $0-2 \mathrm{~s}$ orbitals. Furthermore, compared to the dielectric function spectrum of pure $\mathrm{ZnO}, \mathrm{Yb}$-doped $\mathrm{ZnO}$ has a new peak around $1 \mathrm{eV}$ which decreases and shifted to higher energies with increasing $\mathrm{Yb}$ concentration, It is the same behavior as that of $\mathrm{i}_{2}(\omega)$ in (Jin et al. 2016; Wang et al. 2020) which, according to the study of state density and band structure, can be attributed to the transition of the $\mathrm{Yb} 4 \mathrm{f}$ states to the $\mathrm{Zn} 4 \mathrm{~s}$ states. Therefore, all the photons having a low energy can be absorbed by the doped $\mathrm{ZnO}$, which relatively increased the absorption coefficient in the visible light region.

\section{Absorption, reflectivity and transmittance}

Figures 6 shows the calculated absorption and reflectivity of pure and $\mathrm{Yb}$-doped $\mathrm{ZnO}$ with different concentrations of $\mathrm{Yb}$. As can be seen from Fig. 6a, the pure $\mathrm{ZnO}$ has an absorption peaks around $350 \mathrm{~nm}$ which gradually reduced and shifted toward the higher energy region with increasing $\mathrm{Yb}$ concentration. Meanwhile, in the visible light range of $500-800 \mathrm{~nm}$, the absorption of $\mathrm{Yb}$-doped $\mathrm{ZnO}$ was relatively enhanced compared to that of pure $\mathrm{ZnO}$. This can be attributed to the $\mathrm{Yb}-4 \mathrm{f}$ defect induced near the conduction band minimum. Figure $6 \mathrm{~b}$ shows the reflectivity of pure and $\mathrm{Yb}$ doped $\mathrm{ZnO}$ with deferent $\mathrm{Yb}$ concentrations; it can be observed that all pure and $\mathrm{Yb}$ doped $\mathrm{ZnO}$ structures have a low reflectivity which is less than 0.08 in the visible range. Compared to pure $\mathrm{ZnO}$, the main peak about $400 \mathrm{~nm}$ is blue-shifted. A further decrease in the reflectivity spectrum was observed for $\mathrm{Yb}$-doped $\mathrm{ZnO}$ in the visible region.

\section{Refractive index}


Figure. 8 shows the behavior of the refractive index (n) and the extinction coefficient (k) of ZnO and Yb-doped $\mathrm{ZnO}$ in the wavelength range of $200-800 \mathrm{~nm}$; which is obtained from the relationship between the complex dielectric function and the complex refractive index. As shown in Fig. 8(a), the static value of the refractive index $\mathrm{n}(0)$ at $0 \mathrm{eV}$ of pure $\mathrm{ZnO}$ was 1.59 and the values of $1.92,1.65$ and 1.75 belonged to $4.17 \%, 6.25 \%$ and $12.5 \%$ of $\mathrm{Yb}$, respectively. Furthermore, a higher refractive index was obtained for pure ZnO with value 1.72 at $250 \mathrm{~nm}$ and $410 \mathrm{~nm}$. As we can see, the static refractive index has changed considerably with increasing Yb. As the $\mathrm{Yb}$ concentration increases, the refractive index has changed considerably and shifts to higher energies with a maximum value of 1.76 obtained at $260 \mathrm{~nm}$ for $12.6 \%$ of $\mathrm{Yb}$. However, in the visible range $380-780 \mathrm{~nm}$, the refractive index decreased. This is consistent with the experimental findings of Ref. (LópezMena et al. 2020) which suggest that the decrease in the refractive index can be associated with variations in carrier concentration. Figure 8b shows the extinction coefficient ( $k$ ) for pure ZnO and Yb-doped ZnO. A decrease in the extinction coefficient from 200 to $450 \mathrm{~nm}$ is observed. While the opposite behavior is observed for wavelengths from 405 to $800 \mathrm{~nm}$; this can be attributed to the impurity state induced by $\mathrm{Yb}$ doping, which in line with the calculation results of band structure and calculated transmittance observed in Fig. 3 and Fig. 7.

\section{Conclusion}

In summary, the structural, electronic and optical properties of pure and Yb-doped ZnO

with different $\mathrm{Yb}$ concentrations are studied using GGA + U approximation based on DFT approach. The findings calculated lattice constants and band gap of pure $\mathrm{ZnO}$ are in line with experimental results. The lattice parameters increased as $\mathrm{Yb}$ concentration increased which are in good agreement with the experimental findings. The band gap of $\mathrm{ZnO}$ increased with increasing $\mathrm{Yb}$ content and the Fermi level was shifted to the conduction band, revealing n-type characters with creating new defects related to the $\mathrm{Yb}-4 \mathrm{f}$ states. The total magnetic moment increased and $\mathrm{ZnO}$ has a ferromagnetic property with an optimal concentration of $4.17 \%$ of $\mathrm{Yb}$. The absorption properties have been relatively increased in the visible range; a good transmittance was observed for $4.17 \%$ of $\mathrm{Yb}$ with a blue shift of the main peak compared to pure $\mathrm{ZnO}$. The finding results indicate that $\mathrm{Yb}$ doped $\mathrm{ZnO}$ structures could be used as transparent conductive oxide due to the low absorption, reflectivity and refractive index and a high transmittance in the visible range.

Furthermore, we believe that our findings will provide an effective means for understanding the doping effect in $\mathrm{ZnO}$ and will motivate further theoretical investigations.

\section{Declarations}

\section{Declaration of interests}

The authors declare that they have no known competing financial interests or personal relationships that could have appeared to influence the work reported in this paper.

\section{Acknowledgments}


Special thanks to the International Center of Theoretical Physics (ICTP - Trieste-Italy), University of South Africa-Department of Physics and Africa Graphene Center (South Africa).

\section{References}

1. Achehboune, M., Khenfouch, M., Boukhoubza, I., Leontie, L., Doroftei, C., Carlescu, A., Bulai, G., Mothudi, B., Zorkani, I., Jorio, A.: Microstructural, FTIR and Raman spectroscopic study of Rare earth doped ZnO nanostructures. Materials Today: Proceedings. S2214785321030467 (2021). https://doi.org/10.1016/j.matpr.2021.04.144

2. Bouhouche, S., Bensouici, F., Toubane, M., Azizi, A., Otmani, A., Chebout, K., Kezzoula, F., Tala-Ighil, R., Bououdina, M.: Effect of $\mathrm{Er}^{3+}$ doping on structural, morphological and photocatalytical properties of ZnO thin films. Mater. Res. Express. 5, 056407 (2018). https://doi.org/10.1088/2053-1591/aac4e8

3. Burstein, E.: Anomalous Optical Absorption Limit in InSb. Phys. Rev. 93, 632-633 (1954). https://doi.org/10.1103/PhysRev.93.632

4. Cerrato, E., Zickler, G.A., Paganini, M.C.: The role of $\mathrm{Yb}$ doped $\mathrm{ZnO}$ in the charge transfer process and stabilization. Journal of Alloys and Compounds. 816, 152555 (2020). https://doi.org/10.1016/j.jallcom.2019.152555

5. Chen, J., Zhu, W., Gao, Y., Yang, D., Ma, X.: Electroluminescence from light-emitting devices based on erbium-doped ZnO/n-Si heterostructures: Enhancement effect of fluorine co-doping. Opt. Express. 27, 30919 (2019). https://doi.org/10.1364/OE.27.030919

6. Clark, S.J., Segall, M.D., Pickard, C.J., Hasnip, P.J., Probert, M.I.J., Refson, K., Payne, M.C.: First principles methods using CASTEP. Zeitschrift für Kristallographie - Crystalline Materials. 220, (2005). https://doi.org/10.1524/zkri.220.5.567.65075

7. Daksh, D., Agrawal, Y.K.: Rare Earth-Doped Zinc Oxide Nanostructures: A Review. Rev Nanosci Nanotech. 5, 1-27 (2016). https://doi.org/10.1166/rnn.2016.1071

8. Farhat, S., Rekaby, M., Awad, R.: Synthesis and Characterization of Er-Doped Nano ZnO Samples. J Supercond Nov Magn. 31, 3051-3061 (2018). https://doi.org/10.1007/s10948-017-4548-9

9. Farooq, R., Mahmood, T., Anwar, A.W., Abbasi, G.N.: First-principles calculation of electronic and optical properties of graphene like ZnO (G-ZnO). Superlattices and Microstructures. 90, 165-169 (2016). https://doi.org/10.1016/j.spmi.2015.12.017

10. Harun, K., Yaakob, M.K., Mohamad Taib, M.F., Sahraoui, B., Ahmad, Z.A., Mohamad, A.A.: Efficient diagnostics of the electronic and optical properties of defective $\mathrm{ZnO}$ nanoparticles synthesized using the sol-gel method: experimental and theoretical studies. Mater. Res. Express. 4, 085908 (2017). https://doi.org/10.1088/2053-1591/aa8151

11. Heng, C.L., Wang, T., Su, W.Y., Wu, H.C., Yang, M.C., Deng, L.G., Yin, P.G., Finstad, T.G.: Intense ultraviolet photoluminescent emission from $\mathrm{Yb}$ doped $\mathrm{ZnO}$ thin films on $\mathrm{Si}$ after high temperature annealing. Journal of Alloys and Compounds. 695, 2232-2237 (2017).

https://doi.org/10.1016/j.jallcom.2016.11.072

12. Heng, C.L., Zhao, C.N., Zhang, L., Xiang, W., Su, W.Y., Yin, H.X., Gao, Y.K., Yin, P.G., Finstad, T.G.: Effects of $\mathrm{Yb}$ doping on the structure and near band-edge emission of $\mathrm{ZnO}$ thin films on $\mathrm{Si}$ after high temperature 
annealing. Journal of Luminescence. 222, 117153 (2020). https://doi.org/10.1016/j.jlumin.2020.117153

13. Hengehold, R.L., Almassy, R.J., Pedrotti, F.L.: Electron Energy-Loss and Ultraviolet-Reflectivity Spectra of Crystalline ZnO. Phys. Rev. B. 1, 4784-4791 (1970). https://doi.org/10.1103/PhysRevB.1.4784

14. Jin, Z., Qiao, L., Guo, C., He, Z., Liu, L., Rong, M.: First-priniciple study of electrical and optical properties of (Al,Sn) co-doped ZnO. Optik. 127, 1988-1992 (2016). https://doi.org/10.1016/j.ijleo.2015.10.224

15. Khuili, M., Fazouan, N., El Makarim, H.A., Atmani, E.H., Rai, D.P., Houmad, M.: First-principles calculations of rare earth (RE=Tm, Yb, Ce) doped ZnO: Structural, optoelectronic, magnetic, and electrical properties. Vacuum. 181, 109603 (2020). https://doi.org/10.1016/j.vacuum.2020.109603

16. Li, L., Wang, W., Liu, H., Liu, X., Song, Q., Ren, S.: First Principles Calculations of Electronic Band Structure and Optical Properties of Cr-Doped ZnO. J. Phys. Chem. C. 113, 8460-8464 (2009). https://doi.org/10.1021/jp811507r

17. Li, P., Deng, Sh.H., Li, Y.B., Huang, J., Liu, G.H., Zhang, L.: Aluminum and nitrogen impurities in Wurtzite ZnO: first-principles studies. Physica B: Condensed Matter. 406, 3125-3129 (2011). https://doi.org/10.1016/j.physb.2011.03.079

18. Look, D.C.: Progress in ZnO materials and devices. Journal of Elec Materi. 35, 1299-1305 (2006). https://doi.org/10.1007/s11664-006-0258-y

19. Look, D.C., Reynolds, D.C., Sizelove, J.R., Jones, R.L., Litton, C.W., Cantwell, G., Harsch, W.C.: Electrical properties of bulk ZnO. Solid State Communications. 105, 399-401 (1998).

https://doi.org/10.1016/S0038-1098(97)10145-4

20. López-Mena, E.R., Ceballos-Sanchez, O., Hooper, T.J.N., Sanchez-Ante, G., Rodríguez-Muñoz, M., RenteriaSalcedo, J.A., Elías-Zuñiga, A., Sanchez-Martinez, A.: The effect of Yb doping on ZnO thin films obtained via a low-temperature spin coating method. J Mater Sci: Mater Electron. (2020). https://doi.org/10.1007/s10854-020-04785-7

21. López-Mena, E.R., Jiménez-Sandoval, S.J., Jiménez-Sandoval, O.: Samarium-doped ZnO thin films synthesized by Sol-gel: Structural, optical and electrical properties. Materials Science in Semiconductor Processing. 126, 105648 (2021). https://doi.org/10.1016/j.mssp.2020.105648

22. Ma, X., Wu, Y., Lv, Y., Zhu, Y.: Correlation Effects on Lattice Relaxation and Electronic Structure of ZnO within the GGA+ UFormalism. J. Phys. Chem. C. 117, 26029-26039 (2013). https://doi.org/10.1021/jp407281x

23. Meng, Z., Mo, X., Cheng, X., Zhou, Y., Tao, X., Ouyang, Y.: Interactions between Er dopant and intrinsic point defects of ZnO: a first-principles study. Mater. Res. Express. 4, 035903 (2017). https://doi.org/10.1088/2053-1591/aa6292

24. Moss, T.S.: The Interpretation of the Properties of Indium Antimonide. Proc. Phys. Soc. B. 67, 775-782 (1954). https://doi.org/10.1088/0370-1301/67/10/306

25. Naik, E.I., Naik, H.S.B., Viswanath, R., Kirthan, B.R., Prabhakara, M.C.: Effect of zirconium doping on the structural, optical, electrochemical and antibacterial properties of ZnO nanoparticles prepared by sol-gel method. Chemical Data Collections. 29, 100505 (2020). https://doi.org/10.1016/j.cdc.2020.100505

26. Namgung, G., Ta, Q.T.H., Yang, W., Noh, J.-S.: Diffusion-Driven Al-Doping of ZnO Nanorods and Stretchable Gas Sensors Made of Doped ZnO Nanorods/Ag Nanowires Bilayers. ACS Appl. Mater. 
Interfaces. 11, 1411-1419 (2019). https://doi.org/10.1021/acsami.8b17336

27. Obeid, M.M., Jappor, H.R., Al-Marzoki, K., Al-Hydary, I.A., Edrees, S.J., Shukur, M.M.: Unraveling the effect of $\mathrm{Gd}$ doping on the structural, optical, and magnetic properties of $\mathrm{ZnO}$ based diluted magnetic semiconductor nanorods. RSC Adv. 9, 33207-33221 (2019). https://doi.org/10.1039/C9RA04750F

28. Özgür, Ü., Alivov, Ya.I., Liu, C., Teke, A., Reshchikov, M.A., Doğan, S., Avrutin, V., Cho, S.-J., Morkoç, H.: A comprehensive review of ZnO materials and devices. Journal of Applied Physics. 98, 041301 (2005). https://doi.org/10.1063/1.1992666

29. Perdew, J.P., Burke, K., Ernzerhof, M.: Generalized Gradient Approximation Made Simple. Phys. Rev. Lett. 77, 3865-3868 (1996). https://doi.org/10.1103/PhysRevLett.77.3865

30. Röder, R., Geburt, S., Zapf, M., Franke, D., Lorke, M., Frauenheim, T., da Rosa, A.L., Ronning, C.: Transition Metal and Rare Earth Element Doped Zinc Oxide Nanowires for Optoelectronics. Phys. Status Solidi B. 256, 1800604 (2019). https://doi.org/10.1002/pssb.201800604

31. Senol, S.D.: Hydrothermal derived nanostructure rare earth (Er, Yb)-doped ZnO: structural, optical and electrical properties. J Mater Sci: Mater Electron. 27, 7767-7775 (2016).

https://doi.org/10.1007/s10854-016-4765-1

32. Vanderbilt, D.: Soft self-consistent pseudopotentials in a generalized eigenvalue formalism. Phys. Rev. B. 41, 7892-7895 (1990). https://doi.org/10.1103/PhysRevB.41.7892

33. Wang, J., Shen, T., Feng, Y., Liu, H.: A GGA+U study of electronic structure and the optical properties of different concentrations Tb doped ZnO. Physica B: Condensed Matter. 576, 411720 (2020). https://doi.org/10.1016/j.physb.2019.411720

34. Wen, J.-Q., Zhang, J.-M., Qiu, Z.-G., Yang, X., Li, Z.-Q.: The investigation of Ce doped ZnO crystal: The electronic, optical and magnetic properties. Physica B: Condensed Matter. 534, 44-50 (2018). https://doi.org/10.1016/j.physb.2018.01.035

35. Wu, H.-C., Peng, Y.-C., Chen, C.-C.: Effects of Ga concentration on electronic and optical properties of Gadoped ZnO from first principles calculations. Optical Materials. 35, 509-515 (2013). https://doi.org/10.1016/j.optmat.2012.10.022

36. Xia, C., Wang, F., Hu, C.: Theoretical and experimental studies on electronic structure and optical properties of Cu-doped ZnO. Journal of Alloys and Compounds. 589, 604-608 (2014). https://doi.org/10.1016/j.jallcom.2013.11.066

37. Yao, G.Y., Fan, G.H., Zhao, F., Ma, J.H., Chen, J., Zheng, S.W., Zeng, S.M., He, L.F., Zhang, T.: In assisted realization of p-type C-doped ZnO: A first-principles study. Physica B: Condensed Matter. 407, 35393542 (2012). https://doi.org/10.1016/j.physb.2012.05.019

\section{Figures}



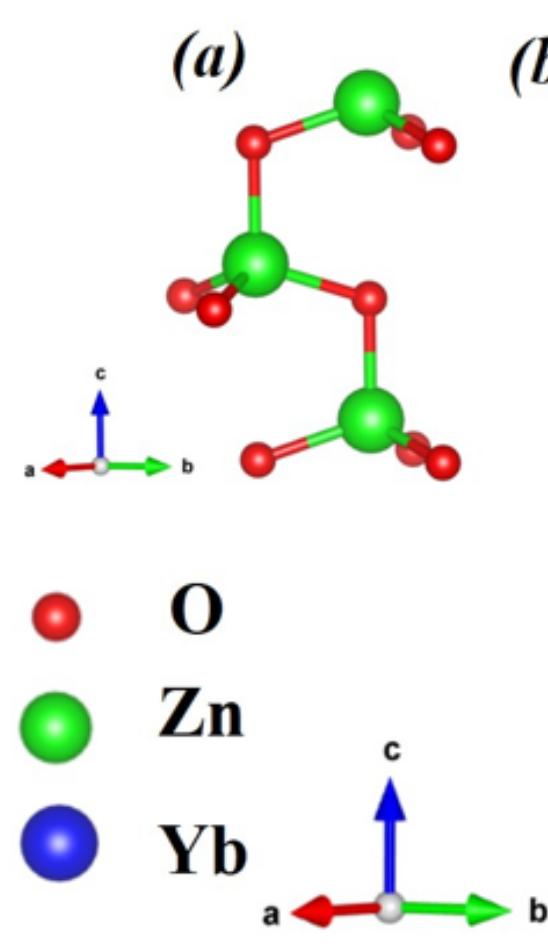

(b)

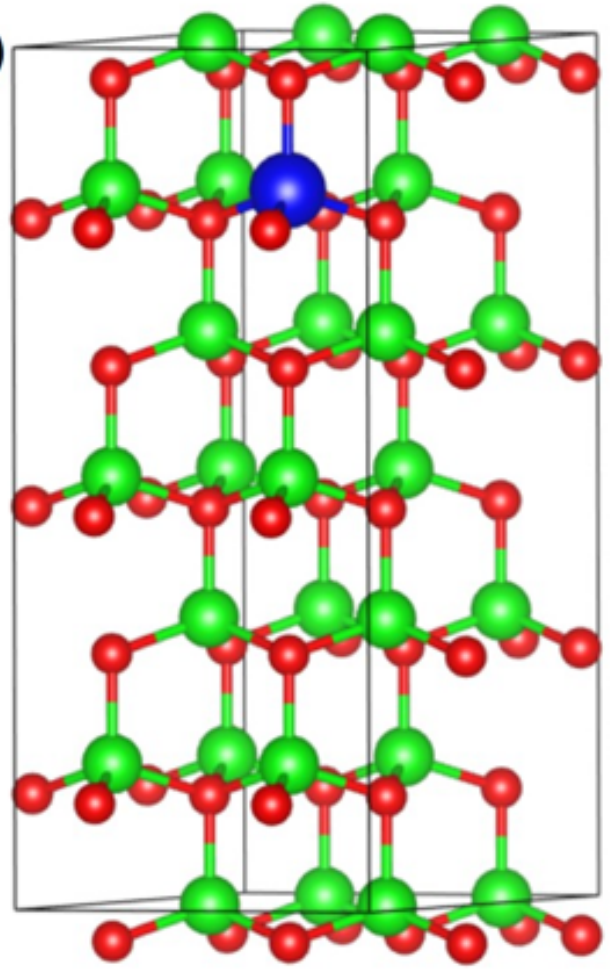

(c)

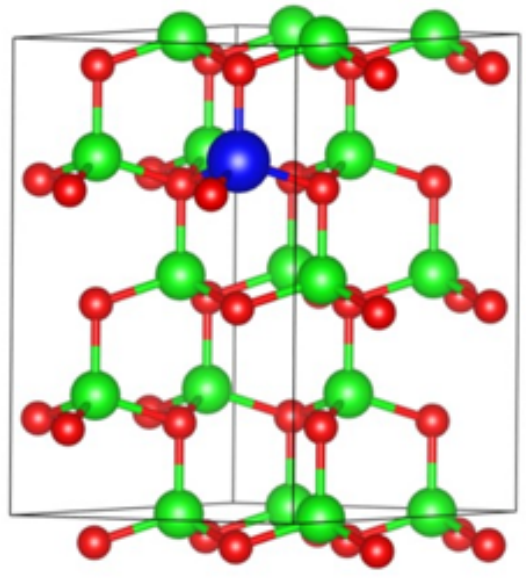

(d)

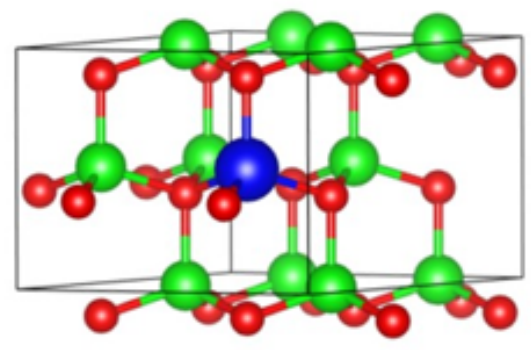

Figure 1

Schematic of the structure of ZnO: a ZnO; b 4.17\% Yb-; c 6.25\% Yb; d 12.5\% Yb. 

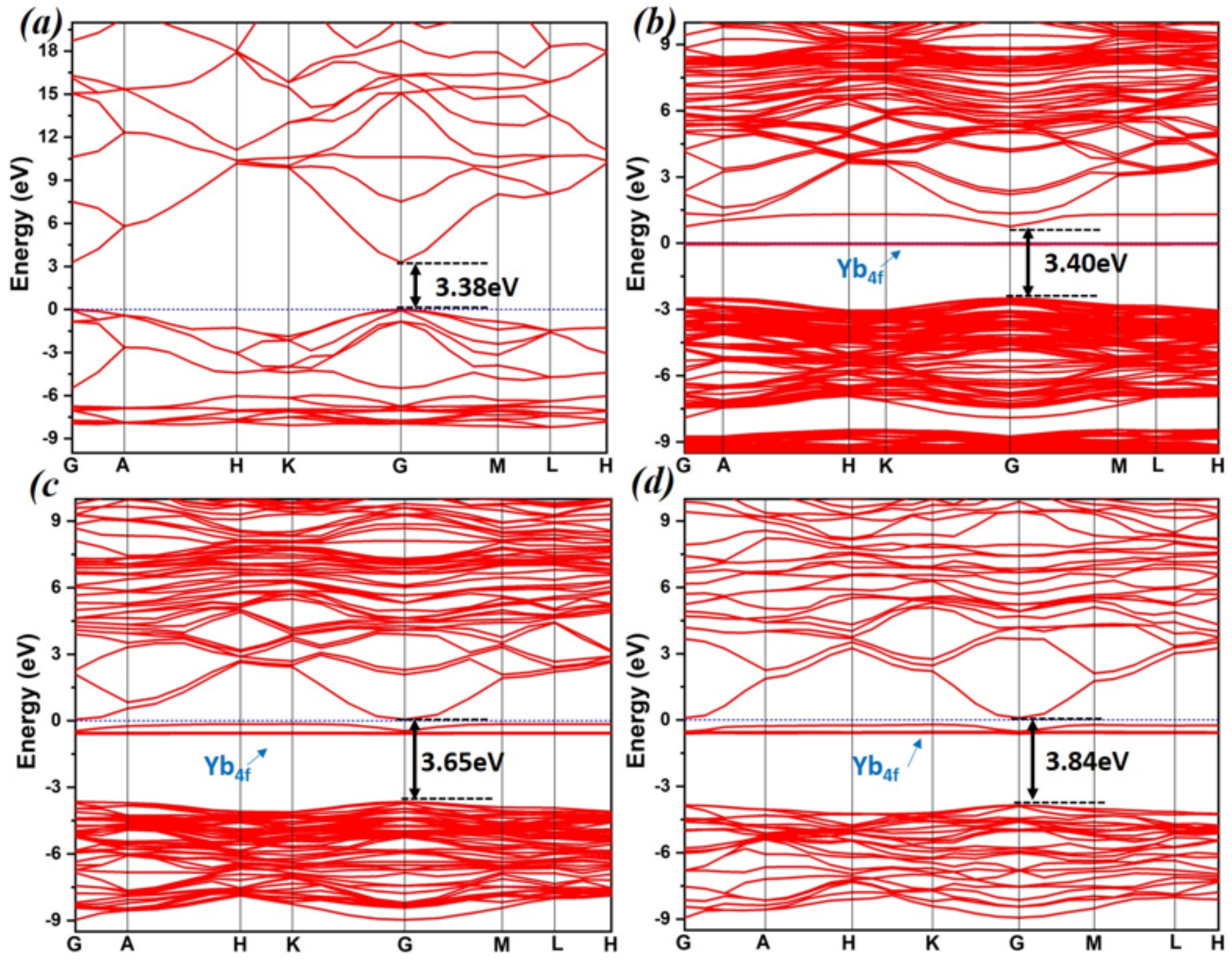

Figure 2

Band structures of pure $\mathrm{ZnO}$ and $\mathrm{ZnO}$ doped systems, where the Fermi level is set to $0: \mathrm{a} \mathrm{ZnO} ; \mathrm{b} 4.17 \% \mathrm{Yb}-; \mathrm{c}$ $6.25 \% \mathrm{Yb} ; \mathrm{d} 12.5 \% \mathrm{Yb}$. 
(a)

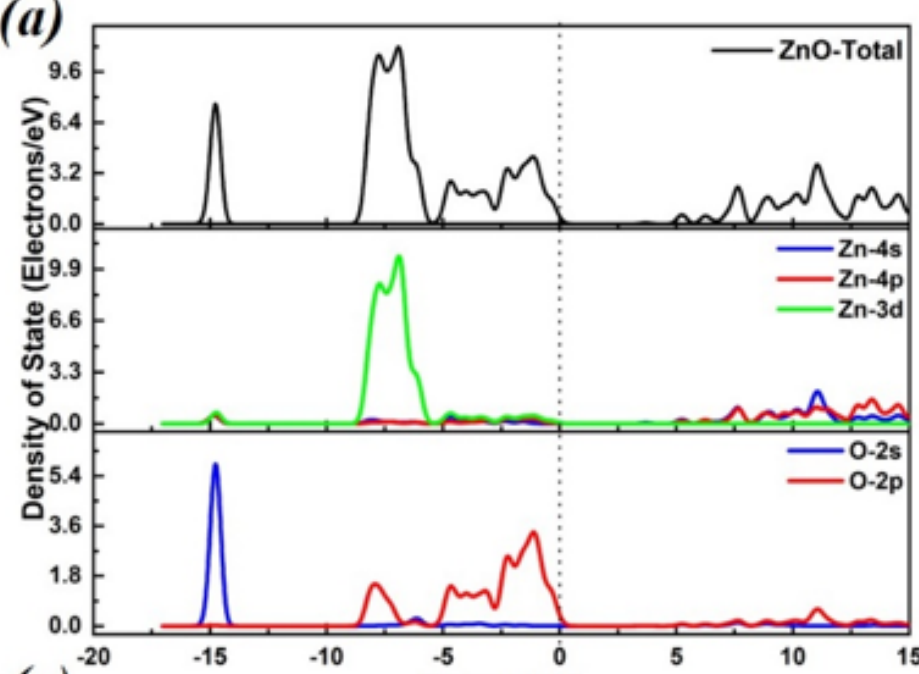

(c)

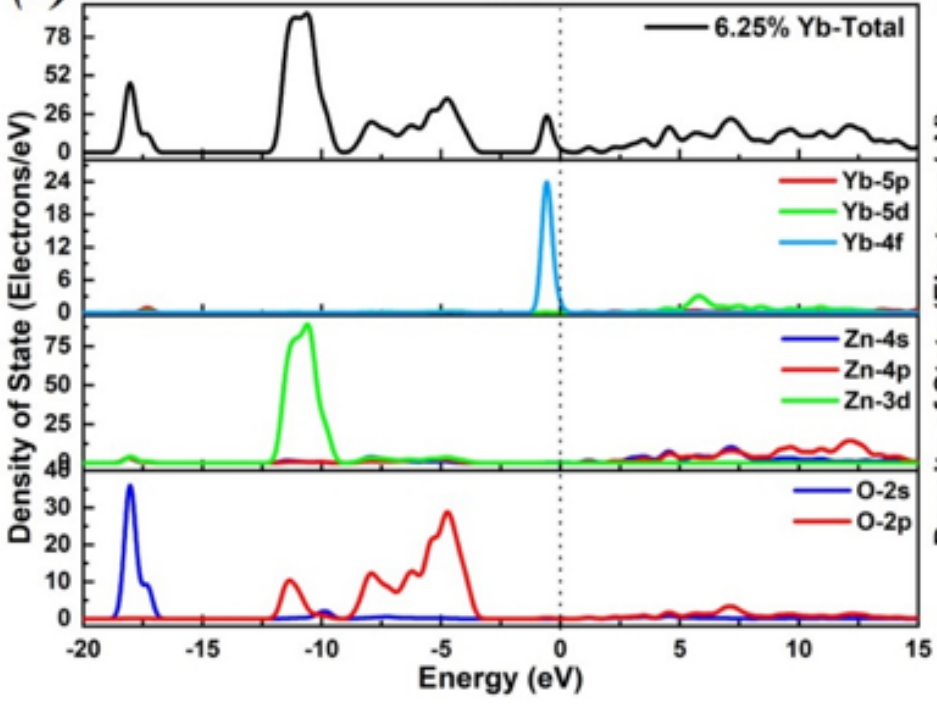

(b)
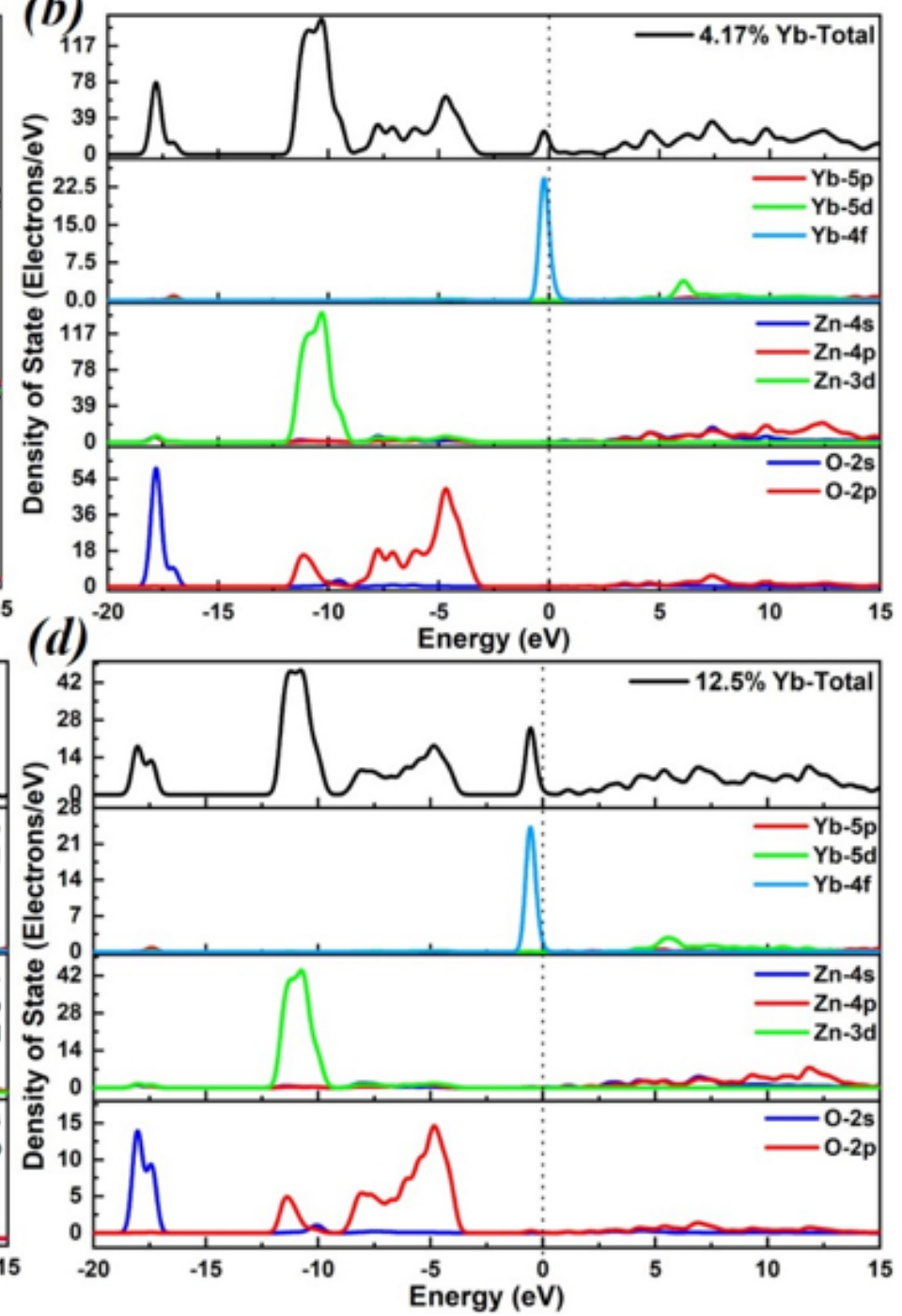

Figure 3

TDOS and PDOS of pure ZnO and ZnO doping systems, where the Fermi level is set to 0: a ZnO; b 4.17\% Yb-; c $6.25 \%$ Yb; d $12.5 \%$ Yb. 

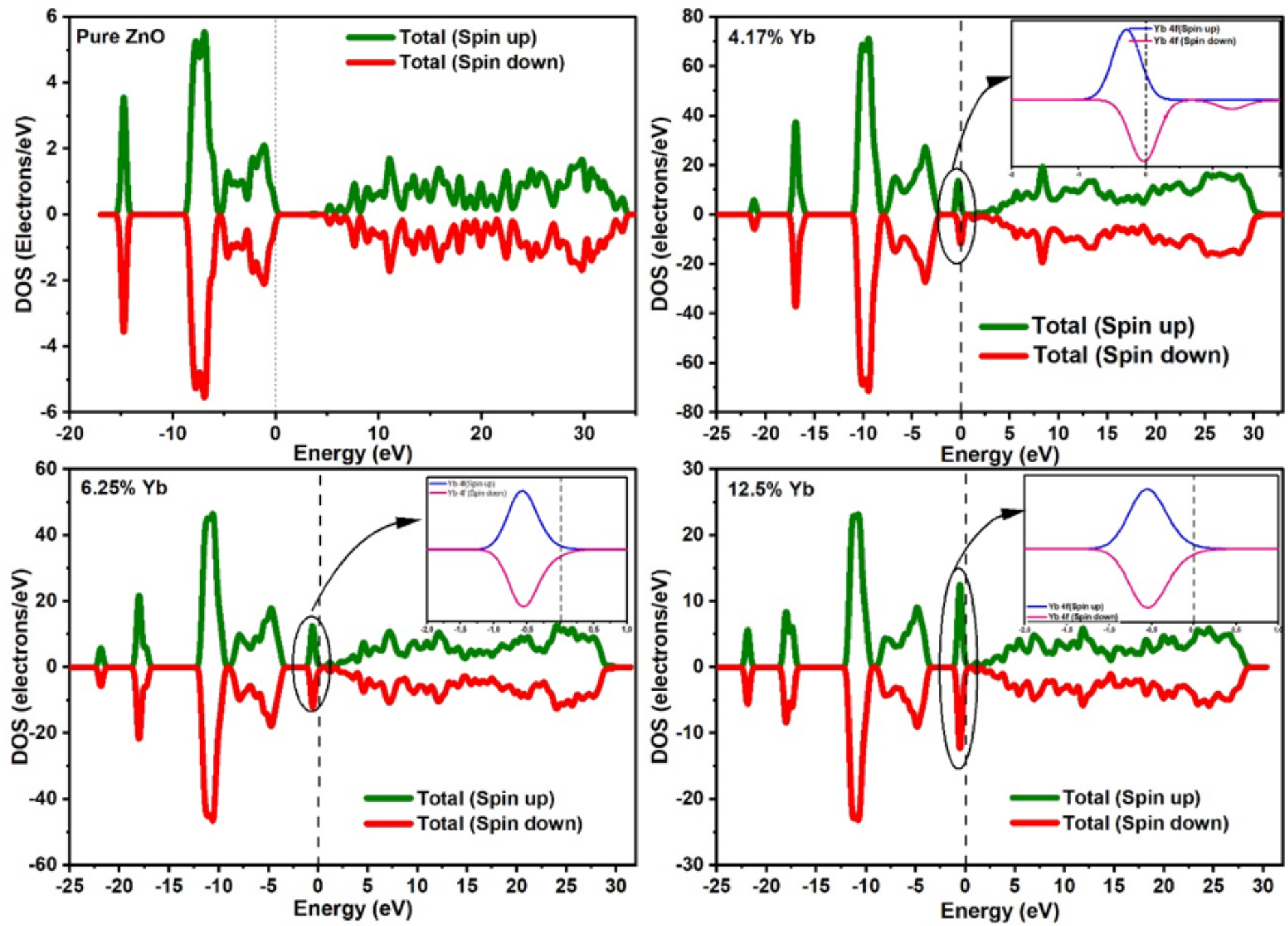

Figure 4

The spin polarized density of states of pure $\mathrm{ZnO}$ and $\mathrm{ZnO}$ doping systems. The vertical lines at zero energy indicate the Fermi level. 


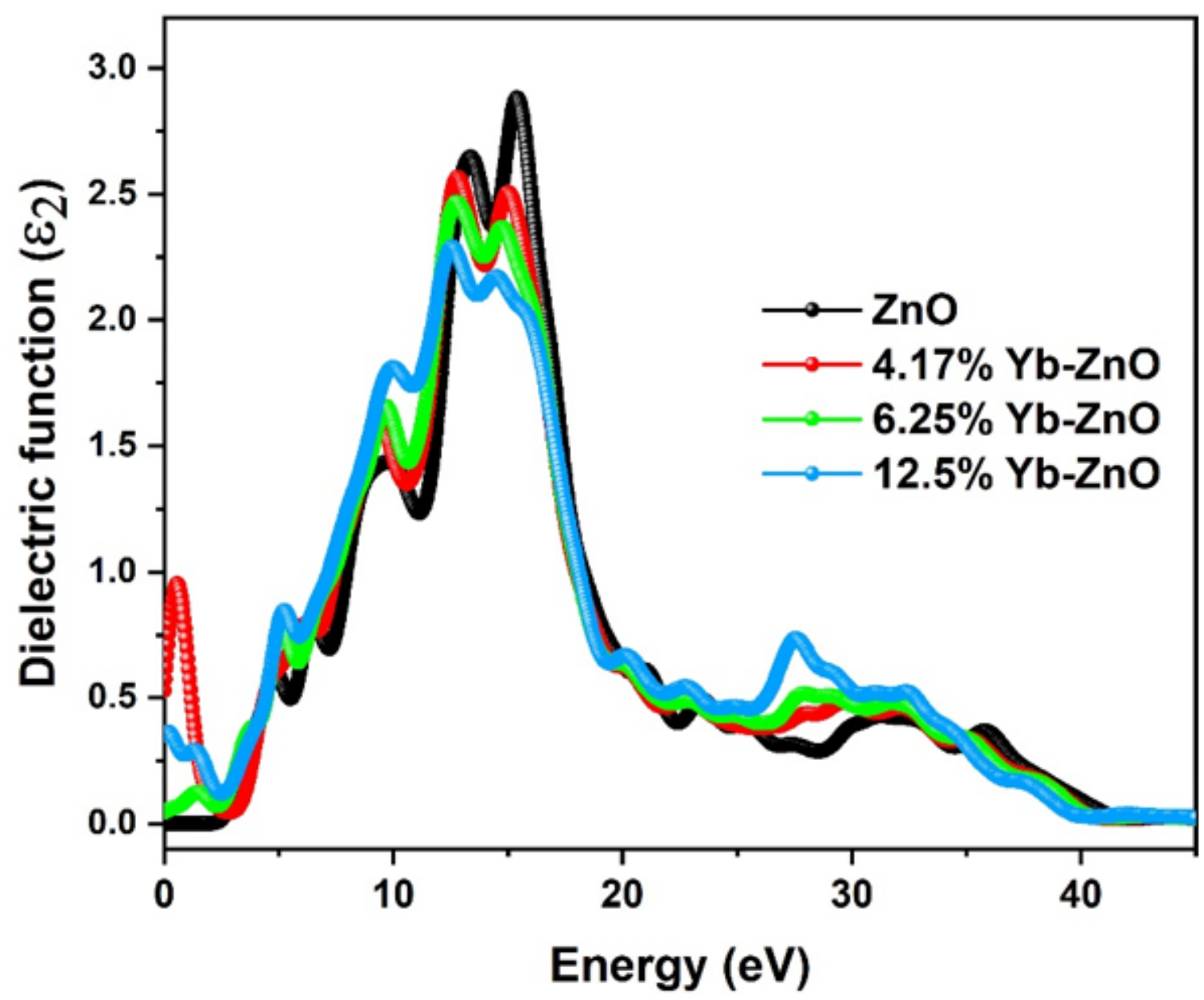

Figure 5

The imaginary part of the dielectric function of pure and $\mathrm{Yb}$ doped $\mathrm{ZnO}$ with different $\mathrm{Yb}$ concentrations.
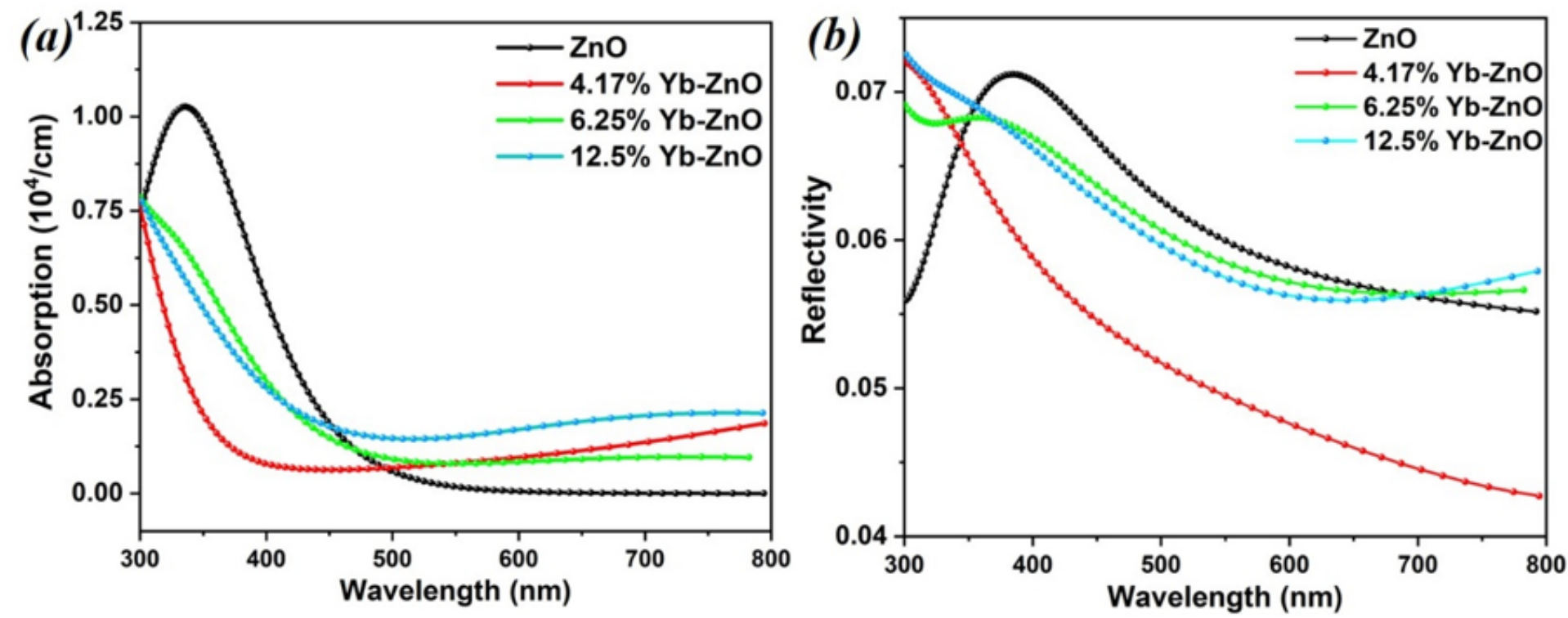

Figure 6 
The optical properties a absorption and $\mathrm{b}$ reflectivity of pure and $\mathrm{Yb}$ doped $\mathrm{ZnO}$ with different $\mathrm{Yb}$ concentrations.

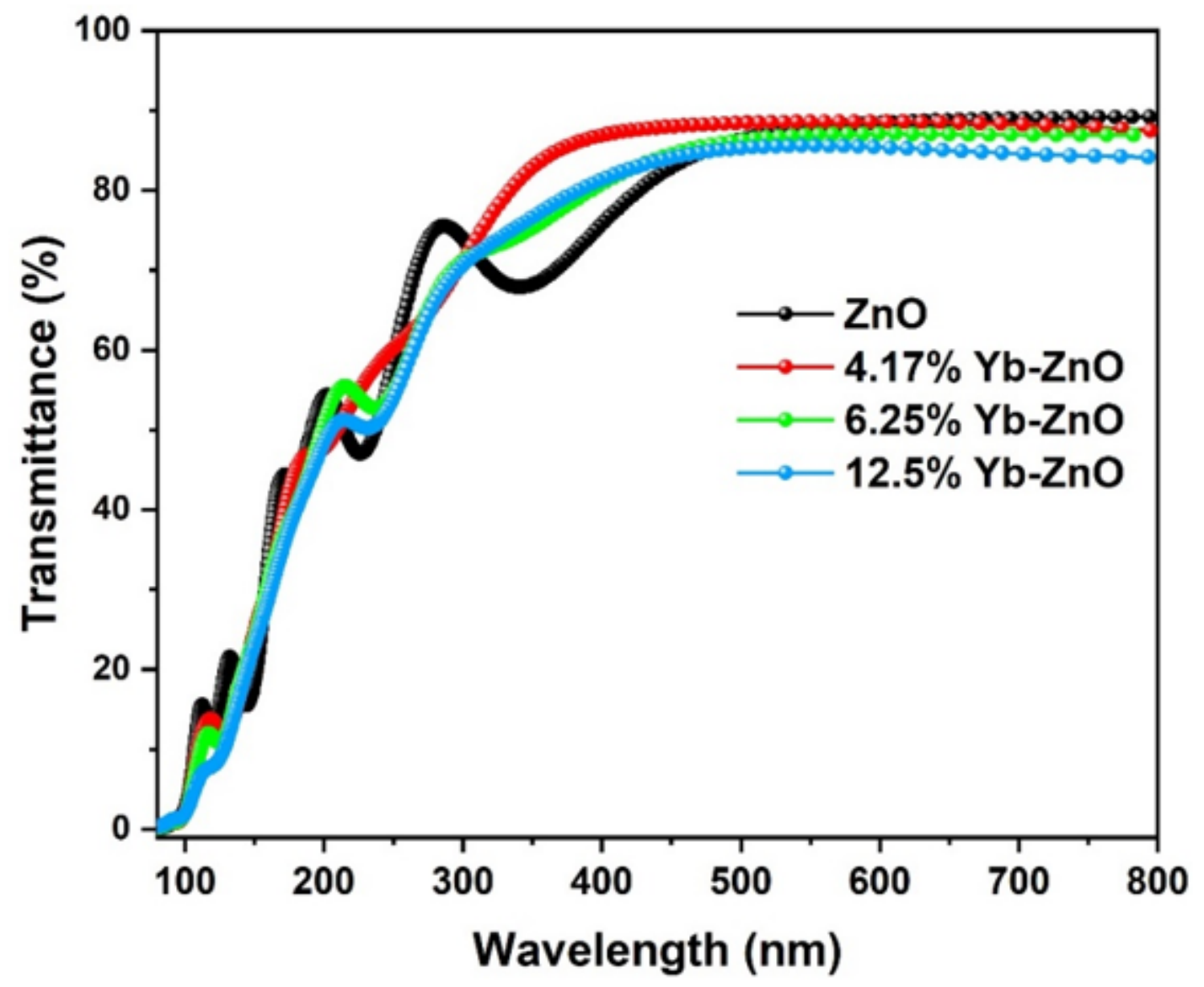

Figure 7

The calculated transmittance of pure and $\mathrm{Yb}$ doped $\mathrm{ZnO}$ with different $\mathrm{Yb}$ concentrations.
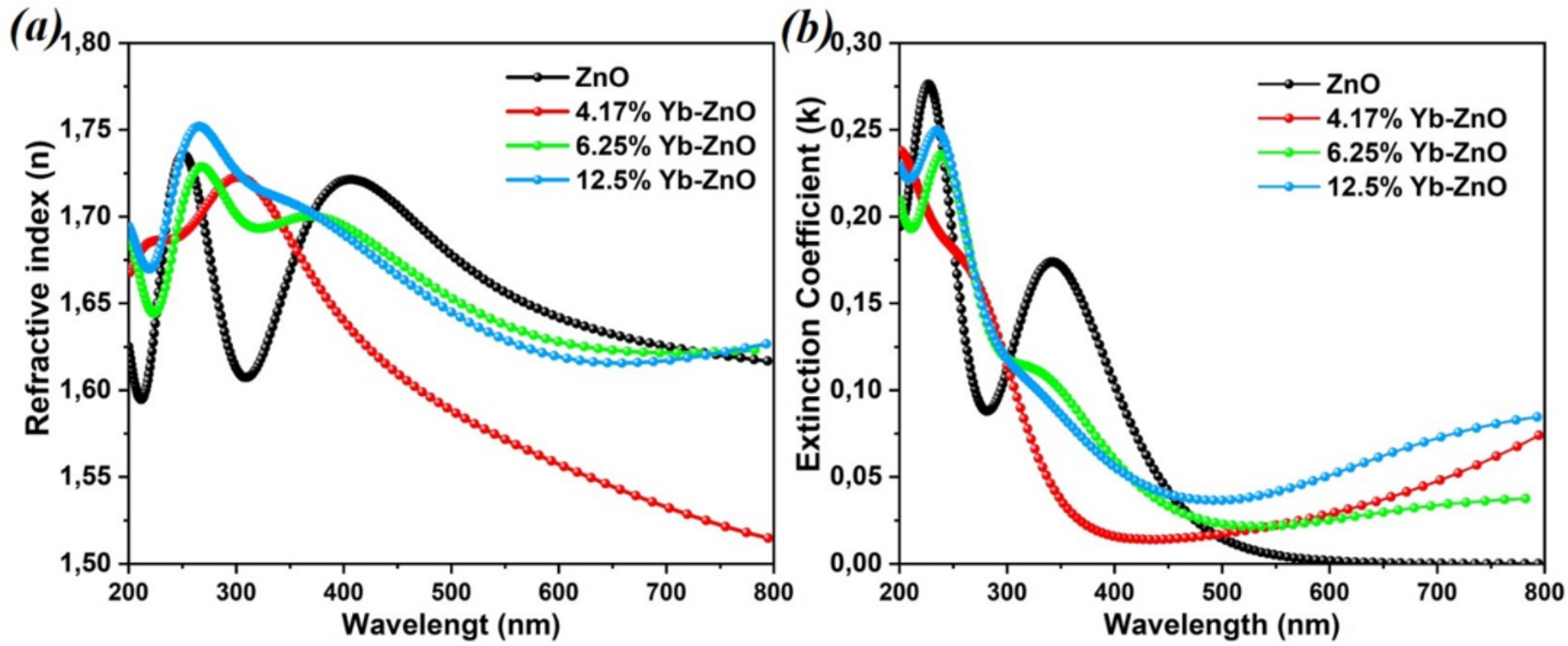

Figure 8 
The calculated (a) refractive index and (b) extinction coefficient of pure and $\mathrm{Yb}$ doped $\mathrm{ZnO}$ with different $\mathrm{Yb}$ concentrations. 